\title{
Douglas-fir is vulnerable to exceptional and recurrent drought episodes and recovers less well on less fertile sites
}

\author{
Anne-Sophie Sergent • Philippe Rozenberg • \\ Nathalie Bréda
}

Received: 7 September 2011 / Accepted: 16 May 2012 /Published online: 21 June 2012

(C) INRA / Springer-Verlag France 2012

\begin{abstract}
- Context Since the 2003 drought and heat wave, there have been many reports of Douglas-fir decline and dieback in France. Given the climate change that is predicted, more frequent drought episodes could induce recurrent decline processes. The nature and background of this threat requires a careful assessment.

- Aims The objectives of this study were: (1) to test the hypothesis that the major climate hazard that accounts for the decline in Douglas-fir growth is drought, and (2) to identify the main vulnerability factors involved.

- Methods Decline and recovery of radial growth were quantified of Douglas-fir in two particularly affected regions with a dendroecological approach; 899 trees were sampled on 58 plots. Mean climate data, ecological and dendrometric stand characteristics were tested in order to identify potential vulnerability factors
\end{abstract}

\section{Handling Editor: Matthias Dobbertin \\ Contribution of the co-authors Anne-Sophie Sergent has contributed to designing the experiment, writing the paper, analysing data. Philippe Rozenberg was co-supervisor of the work and has contributed to data analysing and proofread the paper. Nathalie Bréda was the coordinator of ANR-06-VULN-004, co-supervisor of the work and contributed to experimental design, running the data analysis, computing the water balance and writing the paper.}

A.-S. Sergent $\cdot$ P. Rozenberg

INRA, UR0588, Unit Genetic improvement and forest Physiology, F-45075 Orléans, France

\author{
A.-S. Sergent \\ e-mail: sergent@nancy.inra.fr \\ N. Bréda $(\triangle)$ \\ INRA-UHP UMR 1137 Forest Ecology and Ecophysiology Unit, \\ F-54280 Champenoux, France \\ e-mail: breda@nancy.inra.fr
}

- Results A clear relationship was evidenced between growth and soil water deficit. A severe decline of radial growth was induced by the 2003 drought and was maintained during subsequent years due to recurrent drought episodes. Growth recovery at the stand level was enhanced by soil nutrient fertility. - Conclusion Radial growth of Douglas-fir is clearly driven by the intensity of drought. In a context of climate change, an adaptive silvicultural strategy is required in order to cope with more frequent drought events. To mitigate the frequency and the intensity of water shortage episodes, site selection must take into account not only local climate characteristic but also soil properties like maximum extractable water content. Soil nitrogen fertility was found to play a key role for an efficient recovery of radial growth after drought episodes and thus must be preserved.

Keywords Dendrochronology · Vulnerability · Decline · Water balance $\cdot$ Douglas-fir $\cdot$ Plantation

\section{Introduction}

During recent years, forest diebacks induced by drought and extreme heat have been reported worldwide (Allen et al. 2010). During 2003, an extreme drought and heat wave affected a large fraction of Western Europe. The year was characterised by a lack of precipitation throughout and by abnormally high temperatures during the summer (Rebetez et al. 2006). These extreme conditions induced a drought that was exceptional in duration, intensity and spatial extent (Bréda et al. 2006). Forests were severely affected and tree mortality and decline were observed throughout Europe (Lorenz et al. 2007; Carnicer et al. 2011). Among coniferous species, which were more severely affected than broadleaved species, Silver fir, Scots pine, Black pine and Douglas-fir exhibited severe visual symptoms like needle 
loss, abnormal coloration or dead branches. Douglas-fir, a species introduced to Europe, is important for wood production. It covers 400,000 ha in France and is particularly valued for high growth rate and timber quality. The first visual symptom detected at the end of summer 2003 was an abnormal coloration of needles. This symptom was the result of damage caused by the high temperatures to needles experiencing a severe stomatal closure induced by early soil water deficit (Bréda et al. 2006). These first symptoms were followed by adverse effects, otherwise known as decline, including needle loss, branch mortality, and even tree mortality. Decline is usually defined as a long-lasting deterioration in visible features of the tree associated with a loss of growth (Manion 1981). Such symptoms and tree mortality were reported in Douglas-fir from 2003 on and for several years afterwards. Similar Douglas-fir declines were reported by the French Forest Health Department after drought episodes during 1989 to 1991 and after the dry year 1996. These reports came mainly from North Western France where these drought events were more severe. After 2003, the decline spread to two highly productive Douglas-fir regions in France, Bourgogne and Midi-Pyrénées.

It is well known that drought is one of the main climate hazards causing forest dieback in broadleaved and coniferous species (Lévy et al. 1987; Solberg 2004; Bréda and Badeau 2008; Bigler et al. 2007; Allen et al. 2010). Indeed, in the context of climate change, it is predicted that drought events will become more frequent and intense (Schär et al. 2004). As a result, the 2003 drought may not be an isolated event but rather the first occurrence of a common climate hazard in the close future (Sarris et al. 2007). The 50-year atmospheric reanalysis Safran has been recently used for the simulation of the past 50 years of water resources over France (Vidal et al. 2010a). A high-resolution retrospective analysis of soil water deficit in France over the last 50 years, based on the Safran-Isba-Modcou (SIM) hydrometeorological suite allowed comparing severe drought events that occurred in the past. Extreme or recurrent drought events occurred in France, resulting from multi-year precipitation deficits (1989-1990) or short hot and dry periods (2003) (Vidal et al. 2010b). They have severely impaired forest crown condition and increased mortality in France as reported by the Forest Health Department. Future drought episodes that are inducing recurrent diebacks are likely to reduce forest productivity and affect species distribution (Parmesan and Yohe 2003; Mueller et al. 2005). To assess future risks of Douglas-fir growth decline, it is necessary to: (a) quantify the intensity of water shortage that induces growth decline; (b) identify the factors of vulnerability of Douglas-fir stands to drought. Vulnerability is a central concept in climate change research and is defined as the degree to which a system is likely to experience harm due to the exposure to a hazard (Turner et al. 2003). In the case of growth decline in Douglas-fir, we hypothesised that the relevant climate hazard was soil water shortage and that ecological conditions and silviculture are vulnerability factors. The present study aimed at testing these hypotheses.

To our knowledge, no drought-related decline of Douglasfir has yet been reported in the international scientific literature. Only three Douglas-fir decline episodes have been reported, two in the species' natural range and one in the Netherlands: two remained unexplained and the third one was related to frost damage (Carter et al. 1984; deKort 1993; Reich and Kamp 1993). However, Douglas-fir growth in its natural range is largely controlled by water and nutrient availability (Nigh 2006; Chen et al. 2010). Despite the fact that tree decline is usually caused by complex combinations of factors (Manion 1981), few studies have analysed the relative importance of all factors potentially involved (Suarez et al. 2004; Galiano et al. 2010; Vilá-Cabrera et al. 2011).

Radial growth of Douglas-fir was significantly reduced in France during 2003 (Martinez-Meier et al. 2008, Girard pers. comm.) but a later growth reduction during the subsequent period of decline has not yet been investigated. In this paper, the two most severely affected French Douglas-fir production-regions, Bourgogne and Midi-Pyrénées, were investigated with a dendroecological approach coupled to water balance calculation. The latter aimed at quantifying drought intensity and comparing it to earlier water shortage events. Water balance calculation was preferred to standard statistical tools such as response function analysis relating radial growth and monthly temperature and precipitation. Dendrochronology allows for a retrospective detection, dating and quantification of changes in tree growth associated with the decline. Site conditions and stand parameters were collected as potential vulnerability factors involved in the growth decline. The water balance calculated for each stand was used to quantify the intensity of the drought (Granier et al. 1999). Two sets of questions were addressed in this paper:

At regional level Was inter-annual variation in radial growth of Douglas-fir linked to soil water balance? Was radial growth reduced since 2003? If the radial growth was reduced, should the intensity and the duration of this reduction be interpreted as a decline? Has Douglas-fir growth increased recently, recovering to its pre-2003 level?

At the stand level Does the inter-annual variability in soil water balance explain the variation of growth, especially during a period for growth decline? Do ecological site conditions or silviculture act as vulnerability factors to growth decline and recovery after drought?

Finally, we propose models of growth decline and growth recovery after drought events based on identified vulnerability factors. 


\section{Material and methods}

\subsection{Study area and sampling strategy}

Two French regions where Douglas-fir is grown commercially were selected: Bourgogne, located in North-Eastern Massif-Central; and Midi-Pyrénées, located in Southwestern France (Fig. 1). Thirty planted stands were selected in each region. The sampling was done following a stratified procedure according to: (1) the area covered by Douglas-fir in each ecological region; (2) the local site condition (bedrock, mean annual precipitation); (3) the health of stands as assessed visually from crown condition (healthy to severe decline including dead trees). The sampled stands were pure planted stands of Douglas-fir, aged of a minimum of 20 years and located on homogenous soils and topography. The provenance of trees is not known. Nevertheless, almost all Douglas-fir planted in France originate from coastal provenances from Washington State and Oregon (USA).

\subsection{Plot location and ecological data collection}

At each site, a dendroecological plot with a radius of $15 \mathrm{~m}$ $\left(700 \mathrm{~m}^{2}\right)$ was established avoiding edges and gaps. The centre of each plot was geo-localized using the GeoExplorer global positioning system (Trimble, Sunnyvale, USA).
Observations were made during 2009, in March and April in Bourgogne and in September and October in MidiPyrénées. A soil pit was dug to describe the soil profile, including depth, texture, coarse element fraction, fine roots fraction in each horizon. Extractable soil water content was calculated using the soil texture coefficient and the coarse element fraction of each layer (Wösten and van Genuchten 1988). The depth of any visible limitation to the penetration of fine roots was recorded. Vegetation was comprehensively surveyed within the plot and used as a bioindicator of trophic richness; only species presence was recorded. The mean Ellenberg index for soil nitrogen fertility (EN; Ellenberg et al. 1992) was calculated for each plot and used as an indicator of trophic richness.

\subsection{Silvicultural description and dendrochronological methods}

Diameter at breast height $(\mathrm{DBH})$ was recorded on all trees. Dominant height was measured on the basis of three of the five trees with the greatest $\mathrm{DBH}$; measurements were taken using a Haglöf Vertex hypsometer (Haglöf, Langsele, Sweden). The social position of each tree was ranked according to their relative height (dominant, codominant, suppressed tree). Crown condition was assessed visually as the fraction of needle loss in $10 \%$ increments. The score of $100 \%$ was

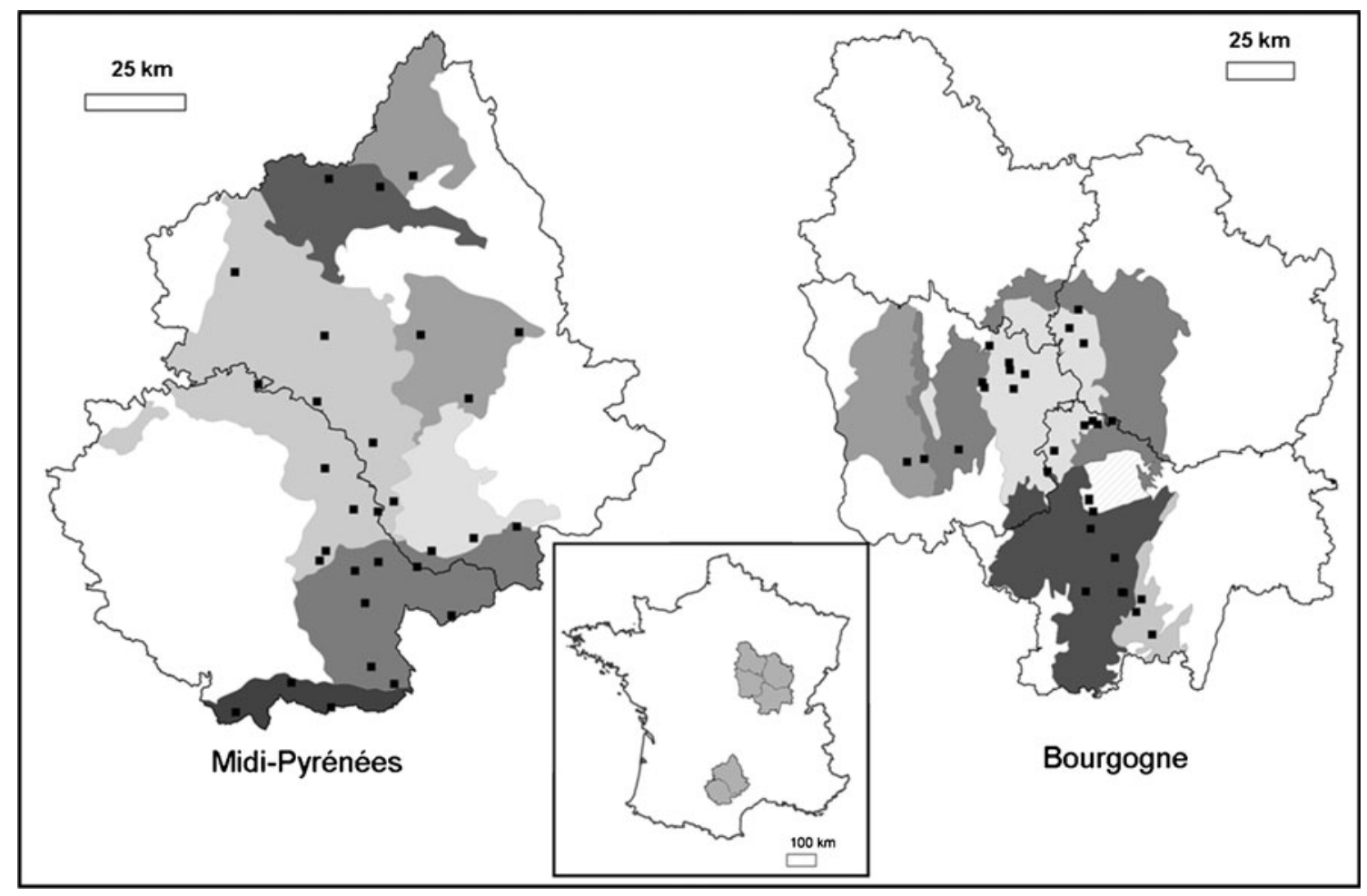

Fig. 1 Geographic location of the 60 plots sampled in the two regions (Bourgogne and Midi-Pyrénées). a Location of the two regions in France. b Location of plots in the six ecological regions in Bourgogne. c Location of plots in the seven ecological regions in Midi-Pyrénées. Each ecological region corresponds to one patch of grey level 
reserved for dead trees. The intensity of recent sanitary thinning was estimated: (1) in the field, as the number of trees thinned since 2003 by counting and measuring the diameter of trees at the last intervention and (2) on the basis of thinning dates since 2003 provided by the forest owners as a result of a specific inquiry. This information was used to estimate the stand density in 2003 before any sanitary thinning following the decline. Older silvicultural information was collected in management plans and before 2003'stand basal area was compared to silvicultural norms in order to identify overdensities according to tree age.

The Site-Index (SI) at 50 years was calculated from a relationship established for French stands (Eq. 1) where $H_{\text {dom }}$ is the dominant height in meters and Age, the age of the tree since germination, in years.

$$
\mathrm{SI}_{50}=\frac{10.905-0.2182 \times \mathrm{Age}+\frac{H_{\mathrm{dom}}}{\left[1-\exp \left(-\left((2.546 \times \mathrm{Age})^{0.2882}\right)\right)\right]^{22.9077}}}{1.5035}
$$

Fifteen trees were cored to the pith in order to measure annual radial growth. The cored trees were randomly selected from the pool of dominant and codominant individuals in each stand. The representativeness of the cored trees was assessed by comparing the mean percentage of defoliation at the plot level with that of the cored trees. The mean observed bias was very low in the two regions, $3.2 \%$ in Bourgogne (maximum $13.7 \%$ ) and $1.5 \%$ in MidiPyrénées (maximum $7.4 \%$ ). A total of 926 trees were cored at breast height using a mechanical Pressler borer of $5 \mathrm{~mm}$ diameter. Ring width was measured using the image analysis software Windendro (Guay et al. 1992). Ring width series were cross-dated using Interdat software (Dupouey J.L., pers. com.). Basal area increment (BAI) was computed from ring width and used to characterise radial growth. The mean annual BAI was calculated for each plot. To allow growth comparison between plots of different ages, all series were standardised. Trends in radial-growth-time-series that may have been related to age and stand dynamics were removed for each plot series using a cubic smoothing spline with a $50 \%$ frequency response cut-off of 20 years (Cook and Perters 1981). The cubic smoothing spline was fitted to all the data from the period before 2003 as illustrated from an example (Fig. 2) and was predicted for the period 20032008. The objective was to quantify growth reduction during the period 2003-2008 compared to reference growth. Year and cambial age were indistinguishable within plots because all trees were the same age, so the trend removed by the spline standardisation represented the effects of a combination of ageing, silviculture and low frequency climatic signals. Final chronologies at the plot level were prepared by averaging the annual residuals to yield a growth index (GI) expressed as a percent of the expected growth under

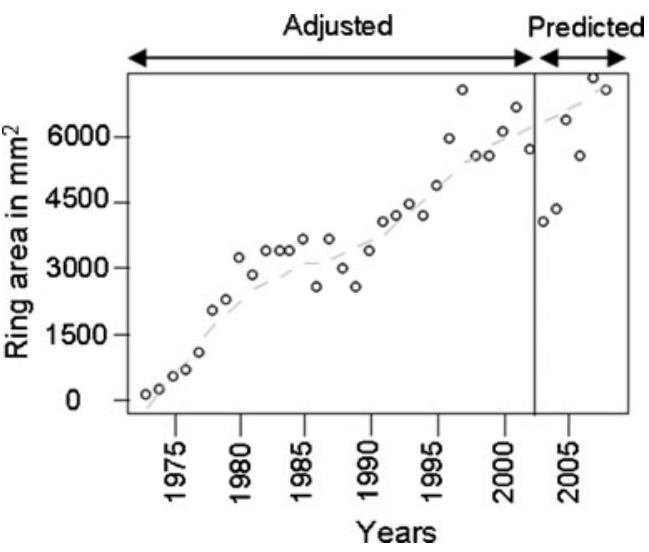

Fig. 2 Example of a basal area increment curve starting after plantation, the standardisation model adjusted to calculate the growth index before 2003 and extrapolated afterwards to compute growth index between 2003 and 2008

average conditions. At the end, 58 plots were used for data analysis. Every mention of growth in the text refers to this radial growth index.

\subsection{Climatic data and soil water balance}

Monthly averaged weather records over 1971-2000 were used to describe mean temperature and precipitation at each site. Data were extracted using the geographical site position from the $1 \mathrm{~km} \times 1 \mathrm{~km}$ grid-based climatic model AURELHY. Annual and seasonal data were obtained by summing or averaging these monthly data. Second, daily climatic data for precipitation, temperature, air humidity, wind speed and global radiation were collected from the nearest MétéoFrance weather station in order to calculate soil water balance day after day from 1989 to 2008 (last ring). Soil water deficit was calculated using the daily water balance model for forests, Biljou $\subset$ (Granier et al. 1999). This processbased model was used to calculate daily water fluxes (interception, transpiration, evapotranspiration, drainage) and soil water content every day from 1989 to 2008. Soil (maximum extractable water, bulk density, and water content at permanent wilting point for each soil layer) and stand parameters (leaf area index-LAI, fine root distribution) were quantified for every stand. Sapwood width was measured in the cores and sapwood area estimated from $\mathrm{DBH}$, with a relationship established on 423 healthy trees cored during this study and in a provenance trial (data not shown). The accuracy of the sapwood area/DBH relationship was verified by comparison with other relationships for Douglas-fir (Marshall and Waring 1986; Brix and Mitchell 1983; St. Clair 1993). Tree leaf area (LA) was derived from sapwood area with an allometric relationship (Marshall and Waring 1986). LA was calculated for each tree present during 2003 according to the stand composition reconstruction. Finally, 
the sum of leaf area of all trees in a plot was divided by plot surface to obtain stand LAI.

Soil water shortage has an impact on trees as soon as relative extractable water (REW) in the soil drops below a critical value of $40 \%$ (Granier et al. 1999), as seen from to transpiration measurements in Douglas-fir stands (Black 1979; Aussenac et al. 1982; Granier 1987). Following Granier et al. (1999), daily soil water balance was used to compute daily values of soil water content, and from these values duration, and precocity of soils water deficit (i.e., when REW was below $40 \%$ ) were derived over each year. By construction, the day by day computation of soil water content includes temporal autocorrelation as REW is never reinitialised.

\subsection{Analysis methods}

\subsubsection{Relationship between growth index and soil water deficit at regional scale}

The relationship between mean annual intensity of soil water deficit and mean annual growth index was examined at the regional scale using a linear regression for the period 1989-2008. The global relationship for the two regions was tested with a linear ANOVA model, by means of the aov function in the R software (Eq. 2). The statistical significance of the soil water deficit effect and regional effect on growth was tested using the following model:

$\mathrm{GI}_{j k} \sim \mu+\mathrm{IS}_{j}+R_{k}+\mathrm{IS}_{j} \times R_{k}+\varepsilon_{j k}$

where GI is the growth index, $\mu$ is the mean of GI, IS is the soil water deficit effect during year $j, R$ is the regional effect of region $k$ and $\varepsilon$ is the additive error term.

\subsubsection{Growth and soil water deficit during decline and recovery periods at different scales}

In each region, the difference between growth index and expected growth was examined annually during the period 2003-2008 by means of a paired $t$ test. The decline period was defined as the consecutive years with growth below expected. The recovery period was defined as consecutive years with growth close or above expected. During both periods, growth was summarised as the mean of all years within the period. To indicate the intensity and duration of soil water deficit, values were cumulated over years. For soil water deficit starting date, values were averaged.

\subsubsection{Growth decline and growth recovery model at plot level}

Univariate relationships between mean growth during both periods (2003-2006, 2007-2008) in each region and soil water deficit were investigated using Pearson's correlations. The relationship between vulnerability factors and mean growth was also examined using Pearson's correlations. Three types of vulnerability factors were tested: (1) drought intensity (2) stand factors (age, $\mathrm{SI}_{50}, \mathrm{EN}$ ), (3) site factors used by foresters to select sites for Douglas-fir plantation (mean climate and elevation). Thinning intensity since 2003 is not a vulnerability factor but its potential role in growth recovery must be taken into account in recovery models. General linear models (Eq. 3) were used to study the relationship between plot characteristics, soil water balance and growth index. Prior to analyses, normality and lack of heteroscedasticity were verified. Only the variables showing a significant relationship with the growth index (GI) were included in the initial set of explanatory variables. Some additional analyses were conducted using Pearson's correlation coefficients and analysis of variance to examine the association between pairs of variables. Where there was an autocorrelation between variables, only one of them was included in the initial set.

The following relationship was assumed:

$\mathrm{GI}=\beta 0+\beta 1 \times \chi 1+\ldots+\beta n \times \chi \mathrm{n}+\varepsilon$

where GI is the growth index, $\chi 1 \ldots \chi^{n}$ are variables corresponding to soil water deficit, ecological and dendrometric variables, $\beta 1 \ldots \beta n$ represent model coefficients and $\varepsilon$ is the additive error term.

Model selection relied on a stepwise selection procedure based on the Akaike Information Criterion (AIC), conducted using the stepAIC function in R. Parameters of all fitted models were estimated using maximum likelihood methods. All statistical analyses were performed using R software (R Development Core Team 2008).

\section{Results}

3.1 Soil water deficit as the driver of inter-annual variation in growth index

Inter-annual variation in radial growth mirrored soil water deficit at the regional scale (Fig. 3a, b). Values of growth index above expected were associated with a low soil water deficit during the growing season, while values below expected were associated with soil water deficits above 45 (Fig. 3). No time lag was detected between water deficit and growth response.

Inter-annual variation in growth index was negatively correlated with inter-annual variation in the intensity of soil water deficit during the period 1989-2008 (Fig. 4). The general relationship estimated for the two regions combined was also highly significant $\left(p<0.0001, R^{2}=0.63\right)$. No effect of region or interaction between region and soil water deficit was found ( $p=0.85$ and 0.59 , respectively). Unexpectedly, the trees from the two regions were subjected to similar 

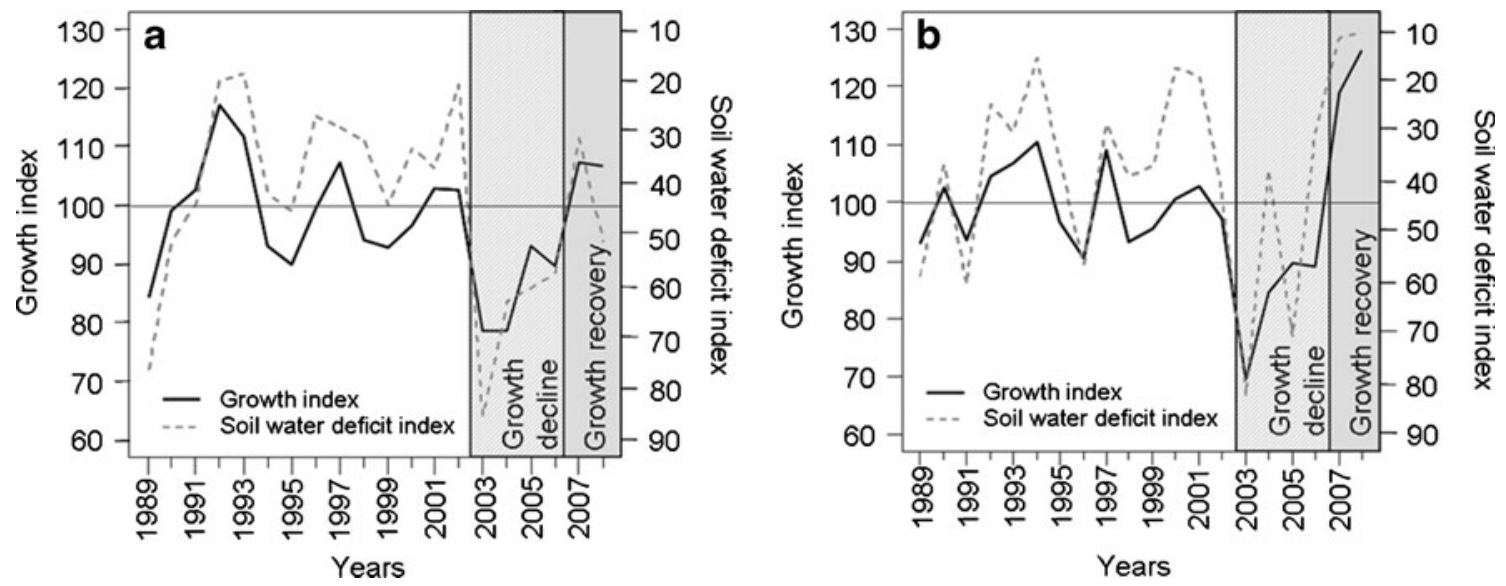

Fig. 3 Inter-annual variations in the growth index (master series, $n=462$ trees in Midi-Pyrénées and $n=437$ trees in Bourgogne) and mean intensity soil water deficit in each region ( $n=29$ plots per region). a Variation in Midi-Pyrénées, $\mathbf{b}$ variation in Bourgogne

ranges of soil water deficit, in spite of contrasting soil properties and local climate.

\subsection{Severe growth decline during 2003-2006 followed} by a growth recovery period

In the two regions, 2003 displayed the highest soil water deficit of the 1989-2008 period, with similar values (83 in Midi-Pyrénées and 82 in Bourgogne). This extremely dry year also corresponded to the lowest growth in the two regions, as illustrated by the master series (Fig. 3a,b). In Bourgogne, the growth index in 2003 reached $69.5 \%$ of expected growth. The growth index in Midi-Pyrénées was higher (78.5\% of expected). In Midi-Pyrénées, 2003 was followed by 3 years (2004-2006) of severe water shortage. Bourgogne experienced a second dry year in 2005. A strong reduction in growth was observed in the two regions during the period 2003 to 2006 (Fig. 3a, b): growth index was significantly lower than expected; the only exception being 2005 in Midi-Pyrénées, when growth was not significantly different from expected. In Midi-Pyrénées, the growth index

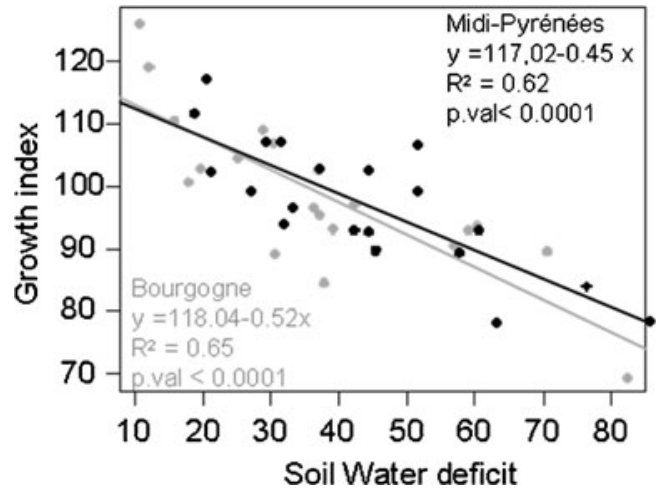

Fig. 4 Relationship between growth index and the intensity of soil water deficit for the two regions. One point corresponds to one year in each region (Bourgogne in grey and Midi-Pyrénées in black) during this period was very similar to that observed in Bourgogne (84.9 and 83.2, respectively; Table 1).

The growth decrease associated with the visual symptoms of decline in 2003 was followed by a recovery period during 2007-2008. In Midi-Pyrénées, during these 2 years of recovery, growth was not significantly higher than expected and these years were characterised by a moderate soil water deficit (Fig. 3a,b). In Bourgogne, growth during the recovery resulted in significantly higher than expected growth and was associated with the lowest soil water deficit recorded during the study period.

\subsection{Vulnerability factors of growth response to drought} at stand level

During the decline period, there were disparities between the average growth at stand level, varying from 61 to $116 \%$ in Bourgogne and 59 to $122 \%$ in Midi-Pyrénées (Table 1). The same trend was observed during the growth recovery period. Some stands did not totally recover; the minimum mean growth index for this period was $71 \%$ in Bourgogne and $63 \%$ in Midi-Pyrénées. The ranges of variation among stands for the growth index, drought characteristics and vulnerability factors are shown in Table 1.

\subsection{The driving factors during decline and recovery}

To test the hypothesis that recent drought events were responsible for Douglas-fir decline, growth reduction and recovery were tested against several features of soil water shortage: intensity of soil water deficit, starting date and duration. In the two regions, mean growth index during the decline period ( $\mathrm{GI}_{2003-2006}$ ) was significantly and negatively linked to cumulated intensity of soil water deficit ( $\left.\mathrm{IS}_{2003-2006}\right)$ and cumulated duration of soil water deficit during the period ( $\mathrm{NJ}_{2003-2006}$; Table 2). A significant positive relationship 
Table 1 Basic statistics for growth, soil water deficit, mean climate, ecological and dendrometric stand characteristics among the 29 sampled stands within each region

\begin{tabular}{|c|c|c|c|c|c|c|c|c|}
\hline \multirow[t]{2}{*}{ Variable name (unit) } & & \multirow[t]{2}{*}{ Abbreviation } & \multicolumn{3}{|c|}{ Bourgogne } & \multicolumn{3}{|c|}{ Midi-Pyrénées } \\
\hline & & & Min & Mean \pm SD & Max & Min & Mean \pm SD & Max \\
\hline \multirow{10}{*}{ Drought hazard } & Growth & & & & & & & \\
\hline & Mean growth index from 2003 to $2006(\%)$ & $\mathrm{GI}_{2003-2006}$ & 61.1 & $83.2 \pm 12.3$ & 116.0 & 59.4 & $85.2 \pm 16.4$ & 121.7 \\
\hline & Mean growth index from 2007 to $2008(\%)$ & $\mathrm{GI}_{2007-2008}$ & 71.1 & $122.7 \pm 35.4$ & 213.8 & 62.9 & $108.7 \pm 26.1$ & 164.3 \\
\hline & Soil water deficit & & & & & & & \\
\hline & Sum of soil water deficit 2003-2006 & IS $_{2003-2006}$ & 14.3 & $221.0 \pm 107.8$ & 463.3 & 147.0 & $272.4 \pm 56.6$ & 393.4 \\
\hline & Sum of soil water deficit $2007-2008$ & IS $_{2007-2008}$ & 0.0 & $22.4 \pm 32.8$ & 140.1 & 14.4 & $84.6 \pm 41.3$ & 164.5 \\
\hline & $\begin{array}{l}\text { Sum of soil water deficit duration } \\
2003-2006 \text { (days) }\end{array}$ & $\mathrm{NJ}_{2003-2006}$ & 84 & $407 \pm 134$ & 624 & 310 & $439 \pm 65$ & 550 \\
\hline & $\begin{array}{l}\text { Sum of soil water deficit duration } \\
2007-2008 \text { (days) }\end{array}$ & $\mathrm{NJ}_{2007-2008}$ & 0 & $57 \pm 59$ & 230 & 73 & $163 \pm 47$ & 255 \\
\hline & $\begin{array}{l}\text { Mean of soil water deficit starting date } \\
2003-2006 \text { (date) }\end{array}$ & $\mathrm{DB}_{2003-2006}$ & 87 & $135 \pm 24$ & 181 & 116 & $140 \pm 15$ & 167 \\
\hline & $\begin{array}{l}\text { Mean of soil water deficit starting date } \\
2007-2008 \text { (date) }\end{array}$ & $\mathrm{DB}_{2007-2008}$ & 113 & $134 \pm 24$ & 205 & 123 & $182 \pm 28$ & 218 \\
\hline \multirow[t]{14}{*}{ Vulnerability factors } & Mean climate $1970-2000$ & & & & & & & \\
\hline & Mean annual temperature $\left({ }^{\circ} \mathrm{C}\right)$ & MAT & 8.8 & $9.7 \pm 0.4$ & 10.3 & 7.6 & $10.3 \pm 1.0$ & 12.1 \\
\hline & Mean annual precipitation (mm) & MAP & 721 & $973 \pm 163$ & 1471 & 843 & $1123 \pm 166$ & 1551 \\
\hline & Mean precipitation March to May (mm) & $P_{\text {spring }}$ & 189 & $245 \pm 37$ & 356 & 241 & $308 \pm 41$ & 412 \\
\hline & Mean precipitation June to August (mm) & $P_{\text {summer }}$ & 185 & $216 \pm 22$ & 281 & 158 & $199 \pm 23$ & 234 \\
\hline & Ecological characteristics & & & & & & & \\
\hline & Elevation (m) & Elevation & 255 & $419 \pm 103$ & 645 & 370 & $667 \pm 154$ & 1014 \\
\hline & Soil nitrogen fertility-Ellenberg index & EN & 2.7 & $4.3 \pm 0.8$ & 6.0 & 2.9 & $4.5 \pm 0.8$ & 5.8 \\
\hline & Depth limit of fine roots $(\mathrm{cm})$ & $\mathrm{DC}$ & 20 & $52 \pm 20$ & 100 & 22 & $63 \pm 24$ & 123 \\
\hline & Soil extractable water (mm) & EW & 26 & $91 \pm 42$ & 166 & 49 & $98 \pm 32$ & 186 \\
\hline & Dendrometric stand characteristics & & & & & & & \\
\hline & Intensity of thinning since 2003 ( $\%$ of tree) & Thinning & 0.03 & $0.35 \pm 0.16$ & 0.63 & 0.00 & $0.18 \pm 0.14$ & 0.43 \\
\hline & Site-Index at 50 years old & $\mathrm{SI}_{50}$ & 27.9 & $35.5 \pm 3.2$ & 42.2 & 27.5 & $32.9 \pm 2.6$ & 36.4 \\
\hline & Age since germination (year) & Age & 28 & $42 \pm 9$ & 75 & 32 & $45 \pm 7$ & 58 \\
\hline
\end{tabular}

between $\mathrm{GI}_{2003-2006}$ and the mean date of the onset of the soil water deficit ( $\left.\mathrm{DB}_{2003-2006}\right)$ was found only in Midi-Pyrénées. A positive relationship was found in the two regions between mean growth index during the recovery period $\left(\mathrm{GI}_{2007-2008}\right)$ and starting date of soil water deficit ( $\left.\mathrm{DB}_{2007-2008}\right)$ during the same period.

3.5 Growth response among stands: vulnerability factors acting before and after drought episodes

Whatever the region, no relationship (Table 2) was found between growth reduction $\left(\mathrm{GI}_{2003-2006}\right)$ and 1970-2000 normal temperature variables. Only in Midi-Pyrénées, a positive relationship was found for mean annual precipitation (MAP) and for seasonal precipitation. In this region, growth exhibited a positive relationship with nitrogen soil fertility (EN) during the decline period. In Bourgogne, growth during the decline period was negatively related to elevation and positively related to soil extractable water (EW). Finally none of the tested dendrometric variables (thinning since 2003, age and Site-Index ${ }_{50}$ ) was significantly linked with growth during the 2003-2006 period.

GI during recovery was significantly correlated to GI during decline. The impact of mean climate differed between the two regions. No significant effect of mean climate was found on $\mathrm{GI}_{2007-2008}$ in Midi-Pyrénées. In contrast, a negative relationship between precipitation (annual and for the seasons separately) and $\mathrm{GI}_{2007-2008}$ was observed in Bourgogne. Similarly, a positive relationship with temperature was also observed. Growth recovery $\left(\mathrm{GI}_{2007-2008}\right)$ exhibited a positive correlation with soil nitrogen (EN) in the two regions, i.e. a faster and more complete recovery of growth on sites with higher N. In addition, growth recovery was larger on shallow soils with a superficial rooting in Bourgogne. In addition, a strong positive correlation was found between EW and growth recovery $\left(\mathrm{GI}_{2007-2008}\right)$ in Midi-Pyrénées. With respect to silviculture in MidiPyrénées, growth recovered better $\left(\mathrm{GI}_{2007-2008}\right)$ in stands 
Table 2 Results of the Pearson's correlations between average growth index during decline (i.e., between 2003 and 2006 GI $2003-2006$ ) and recovery (between 2007 and 2008, $\mathrm{GI}_{2007-2008}$ ) and potential vulnerability factors in the two regions

\begin{tabular}{|c|c|c|c|c|c|c|c|c|c|}
\hline \multirow[b]{3}{*}{ Growth } & \multirow[b]{3}{*}{$\mathrm{GI}_{2003-2006}$} & \multicolumn{4}{|c|}{ Bourgogne } & \multicolumn{4}{|c|}{ Midi-Pyrénées } \\
\hline & & \multicolumn{2}{|c|}{$\mathrm{GI}_{2003-2006}$} & \multicolumn{2}{|c|}{$\mathrm{GI}_{2007-2008}$} & \multicolumn{2}{|c|}{$\mathrm{GI}_{2003-2006}$} & \multicolumn{2}{|c|}{$\mathrm{GI}_{2007-2008}$} \\
\hline & & $\mathrm{x}$ & & 0.44 & $(0.0173)$ & $\mathrm{x}$ & & 0.75 & $(<0.0001)$ \\
\hline \multirow[t]{4}{*}{ Soil water deficit } & IS $_{2003-2006}$ & -0.51 & $(0.0046)$ & ns & & -0.42 & $(0.0193)$ & ns & \\
\hline & $\mathrm{NJ}_{2003-2006}$ & -0.46 & $(0.0120)$ & $\mathrm{ns}$ & & -0.39 & $(0.0316)$ & $\mathrm{ns}$ & \\
\hline & $\mathrm{DB}_{2003-2006}$ & ns & & ns & & 0.35 & $(0.0550)$ & ns & \\
\hline & $\mathrm{DB}_{2007-2008}$ & ns & & 0.57 & $(0.0974)$ & $\mathrm{x}$ & & 0.47 & $(0.0120)$ \\
\hline \multirow[t]{4}{*}{ Mean climate $1970-2000$} & MAT & ns & & 0.37 & $(0.0499)$ & ns & & ns & \\
\hline & MAP & ns & & -0.36 & $(0.0526)$ & 0.44 & $(0.0161)$ & ns & \\
\hline & $P_{\text {Spring }}$ & ns & & -0.39 & $(0.0388)$ & 0.51 & $(0.0042)$ & ns & \\
\hline & $\mathrm{P}_{\text {Summer }}$ & ns & & -0.35 & $(0.0633)$ & ns & & ns & \\
\hline \multirow[t]{4}{*}{ Ecological characteristics } & Elevation & -0.44 & $(0.0170)$ & ns & & ns & & ns & \\
\hline & EN & ns & & 0.48 & $(0.0085)$ & 0.39 & $(0.0347)$ & 0.32 & $(0.0855)$ \\
\hline & $\mathrm{DC}$ & ns & & -0.38 & $(0.0621)$ & ns & & ns & \\
\hline & EW & 0.44 & $(0.0182)$ & ns & & ns & & 0.34 & $(0.0633)$ \\
\hline \multirow[t]{3}{*}{ Dendrometric stand characteristics } & Thinning & ns & & ns & & ns & & 0.41 & $(0.0245)$ \\
\hline & Site-Index 50 & ns & & -0.43 & $(0.0197)$ & ns & & ns & \\
\hline & Age & ns & & ns & & ns & & 0.37 & $(0.0467)$ \\
\hline
\end{tabular}

$x$ indicates no relevant relationship, not tested. Only significant correlations with $p<0.10$ are reported. Values in parentheses indicate the probability

with a high thinning intensity since 2003 and in older stands. In this region, sanitary thinning after 2003 was quite systematic and more intensive in older stands. In Bourgogne, $\mathrm{GI}_{2007-2008}$ was negatively correlated with SiteIndex.

\subsection{Modelling vulnerability of growth to drought}

All significant variables for each region and each period were used as explanatory variables. In Midi-Pyrénées, the stepwise selection procedure used to produce the growth decline model resulted in removal of some explanatory variables ( $\mathrm{DB}_{2003-2006}$, MAP, $\left.P_{\text {spring }}\right)$. The model of growth decline derived for Midi-Pyrénées explained $45 \%$ of the variance of the growth index. Growth was negatively influenced by the intensity of soil water deficit and positively influenced by soil fertility (Table 3 ). The selection procedure did not remove any explanatory variable for Bourgogne. The model explained $37 \%$ of the total variance. Growth was mostly affected by the intensity of soil water deficit and, to a lesser extent, by elevation (Table 3 ).

3.7 Modelling growth recovery after recurrent drought episodes

In Bourgogne, the stepwise selection procedure used to compute the growth recovery model skipped some explanatory variables $\left(\mathrm{DB}_{2007-2008}\right.$, MAT and DC). The model explained $61 \%$ of the variance in Bourgogne. Growth recovery was positively influenced by soil fertility. SiteIndex ${ }_{50}$, previous growth and, to a lesser extent, MAP were also significant variables in the growth recovery model; higher values for those variables were associated with lower growth during the recovery period (Table 3). In MidiPyrénées, the stepwise selection procedure did not remove any explanatory variable. The model of growth recovery explained $72 \%$ of the total variance in Midi-Pyrénées. Previous growth, extractable soil water, mean starting day of soil water deficit during the decline period, intensity of thinning and soil fertility were all positively correlated with growth recovery (Table 3 ).

\section{Discussion}

According to the data collected during this study, variability in the growth of Douglas-fir is mainly controlled by water shortage, at both regional and stand levels. Using a water balance approach in studies of radial growth improves the quantification of local water deficit, taking into account extractable soil water, rainfall interception and evapotranspiration (and not only temperature), as well as stand leaf area index. Our results suggest that cumulated drought episodes severely impair growth, especially if soil water deficit occurs early in the season. Growth recovery occurs only when there is no soil water deficit or a late and limited soil 
Table 3 General linear models for growth decline and growth recovery at the stand level for each region

\begin{tabular}{|c|c|c|c|c|}
\hline Model terms & Estimate & S.E. & $p$ value & $R^{2}$ \\
\hline \multicolumn{5}{|c|}{ Growth during decline period } \\
\hline \multicolumn{5}{|l|}{ Bourgogne } \\
\hline $\mathrm{IS}_{2003-2006}$ & -0.054 & 0.017 & 0.0042 & \multirow[t]{2}{*}{0.37} \\
\hline Elevation & -0.047 & 0.018 & 0.0148 & \\
\hline \multicolumn{5}{|l|}{ Midi-Pyrénées } \\
\hline $\mathrm{IS}_{2003-2006}$ & -0.159 & 0.041 & 0.0006 & \multirow[t]{2}{*}{0.45} \\
\hline EN & 9.460 & 3.075 & 0.0049 & \\
\hline \multicolumn{5}{|c|}{ Growth during recovery period } \\
\hline \multicolumn{5}{|l|}{ Bourgogne } \\
\hline $\mathrm{EN}$ & 24.161 & 6.007 & 0.0005 & \multirow[t]{4}{*}{0.61} \\
\hline Site-Index ${ }_{50}$ & -4.755 & 1.361 & 0.0019 & \\
\hline $\mathrm{GI}_{2003-2006}$ & 0.889 & 0.356 & 0.0199 & \\
\hline MAP & -0.061 & 0.027 & 0.0347 & \\
\hline \multicolumn{5}{|c|}{ Midi-Pyrénées } \\
\hline $\mathrm{GI}_{2003-2006}$ & 0.886 & 0.185 & $<0.0001$ & \multirow[t]{4}{*}{0.72} \\
\hline EW & 0.280 & 0.087 & 0.0035 & \\
\hline Thinning & 35.324 & 19.998 & 0.0901 & \\
\hline EN & 5.863 & 4.155 & 0.1710 & \\
\hline
\end{tabular}

water deficit. This confirms previous dendroecological studies of Douglas-fir in its natural range, indicating that radial growth is primarily limited by growing season precipitation and heat-moisture indices (Griesbauer and Green 2010; Littell et al. 2008; Watson and Luckman 2002). Our results are also consistent with rainfall exclusion experiments, which have shown that the radial growth of mature Douglas-fir is controlled by soil water availability (Aussenac et al. 1984). Soil water deficit leads to stomatal closure, which reduces evapotranspiration and limits carbon uptake, resulting in growth reduction and subsequent growth cessation in the case of persistent water deficit (Aussenac et al. 1984). The higher growth rate during years with low soil water deficit can be explained by a shorter period of stomatal closure coupled to a longer period of cambial activity (Aussenac and Granier 1988). The sharp correlation between soil water deficit and growth highlights the synchrony between growth response and soil water shortage (Black 1979).

Growth reductions during 2003 were relatively severe in Bourgogne and Midi-Pyrénées. The tree rings produced in 2003 were the narrowest measured, corresponding to the driest year observed during the 1989-2008 period. Our results confirm that the growth of coniferous species was severely affected, especially as compared to broadleaved species (Girard, pers. com.). The reduction in growth of $30.5 \%$ in the year 2003 that we estimated in Bourgogne is consistent with other, independent, results obtained for two departments of Bourgogne using data from the National Forest Inventory (Girard pers. com.), where reductions of $26.4 \%$ and $34.3 \%$ were recorded for Douglas-fir in two different areas (Girard, pers. comm.). Our estimation of growth reduction is also consistent with that of Pichler and Oberhuber (2007), who found a reduction of $35 \%$ in 2003 compared to the previous year's radial growth in Scots pine and Norway spruce exposed to a dry inner Alpine climate (Bigler et al. 2006). Jolly et al. (2005) reported the strongest growth reduction in 2003 for Norway spruce of up to $60 \%$, for silver fir of up to $50 \%$ and for common beech of up to $40 \%$, depending of site altitude in Switzerland, but these species are considered as highly drought sensitive.

Severe drought episodes are known to induce: (1) immediate regulation (stomatal closure, reduced carbon assimilation and storage, growth cessation, and reduction of nutrient assimilation and storage) and (2) irreversible damage such as xylem cavitation, premature twig abscission or loss of foliage and fine roots mortality (Bréda et al. 2006). As a consequence, tree ring width is frequently reduced for several years following a 1-year severe soil water shortage. As an example, silver fir in the Vosges Mountains exhibited long-term delayed effects of soil water deficit in the year 1976 for up to 6 years (Becker 1989). Therefore in the present case of Douglas-fir decline, the 2003 drought had a direct effect on tree ring growth that year, while growth decline during subsequent years was affected by the water balance after 2003. In our case, in the two study regions, recurrent drought episodes were observed. Growth decline was induced and maintained by several successive drought episodes and growth recovery was only possible when this severe water deficit ceased. The absence of delayed response of growth to water shortage is also supported by 
the fact that the shape of the relationship between growth and soil water deficit was similar during decline and recovery periods.

During the decline period, the mean annual growth decrease was similar in the two regions. This trend at regional scale somehow masked variations in growth reduction at the stand scale. The differences between stands are mainly explained by the intensity of local soil water deficit, which depends on local precipitation, soil extractable water and leaf area index through both precipitation interception and stand evapotranspiration. Despite the lower soil water deficit during 2007-2008, Douglas-fir growth did not completely recover in some stands. The growth during the recovery period was mainly influenced by the growth during the decline period and by nutrient availability. Possible damage such as needle loss, LAI reduction and hydraulic damage have to be repaired to recover pre-stress functioning (Anekonda et al. 2002). As a result of recurrent drought events, the amount of stored carbohydrates may also be reduced and may not be fully replenished by the end of the growing season. The tree must allocate available stored reserves among the various demands for repair, maintenance, growth and defence (Bréda et al. 2006). In Scots pine submitted to two successive drought events, carbon reserves were depleted as a result of needle loss concurrently to radial growth reduction (Galiano et al. 2011). Reduced growth may indicate limited carbohydrate reserves and, as a consequence, recovery may be delayed or inhibited. The other factor implicated in recovery is nutrient fertility, as demonstrated by the fact that higher values of the EN Ellenberg index were associated with a more efficient recovery. Understory vegetation is known to be useful for classifying soil nutrient regime (Wang 2000), even if functional links between bio-indication and foliar analysis of nutrient content or soil chemical analysis are weak. Otherwise, liming is a practice sometimes used to restore soil mineral fertility and reverse stand decline (van Praag and Weissen 1986; Misson et al. 2001). Nitrogen fertilization of Douglas-fir improves otherwise foliage efficiency (Mitchell et al. 1996) and water use efficiency (Jassal et al. 2010), but its impact on radial growth recovery after water shortage has to be tested. The link between growth recovery and nutrient availability in the two regions indicates an interaction between tree mineral nutrition and resistance or resilience to drought. As a consequence, stand management should focus on preserving soil fertility. Premature stem harvesting, sometimes suggested to reduce climatic risks, impairs nutrient balance; in Douglas-fir this is particularly true for harvesting when trees are less than 60 years old (Ranger and Turpault 1999). Rotation shortening needs nutrient additions to be sustainable (Marques et al. 1997).

Other vulnerability factors differed between the two regions. In Midi-Pyrénées, the effect of thinning since 2003 suggests that the remaining trees took advantage of reduced competition by accessing resources that became available. Thinning directly influences the water balance (Bréda et al. 1995) by reducing leaf area index: interception and evapotranspiration decrease leading both to an increase in soil water, and lower duration and intensity of soil water deficit, as demonstrated for Douglas-fir by Aussenac et al. (1982) and Aussenac and Granier (1988). By increasing growing space, thinning reduces the impact of drought and leads to a faster recovery (Kohler et al. 2010); this may be because of the increased ratio of rooted soil volume to transpiring leaf area for individual trees.

In Bourgogne, growth recovery after recurrent drought events was also explained by reduced growth during the decline period and by soil nitrogen fertility. However, thinning had no effect on growth during the recovery period in Bourgogne, despite the high stand density due to delayed silvicultural interventions in most stands. This contrast with Midi-Pyrénées is probably due to the fact that water availability was not the major limiting factor during this period in Bourgogne. As 2007 and 2008 were rainy years in Bourgogne, the remaining trees did not need the extra water made available by thinning. The other factors (Site-Index, average rainfall) were expected to enhance growth in reality had an opposite effect. Site-Index is used by forest managers to describe site quality in terms of height growth performance. A complementary analysis (data not shown) showed that Site-Index in Bourgogne is mainly controlled by water balance components. Indeed, a high Site-Index was related to low soil water deficit averaged over the 1989-2008 period (data not shown), due to higher rainfall and lower temperature, and deeper fine root penetration. An earlier study reported for Pinus pinea that soil texture and water retention controlled site index (Bravo-Oviedo and Montero 2005). Unexpectedly, radial growth recovery on sites exhibiting the lowest water constraints (higher site-index, higher average rainfall) was more limited after severe drought events, suggesting that such trees are not acclimated to drought: they probably allocated fewer resources to belowground growth and to non structural carbohydrate storage. The results presented here are applicable to all French Douglas-fir plantations close to rotation age and mature stands (and some of them are now naturally regenerated), as all the plantations in France were achieved using coastal provenances from Washington State and Oregon (USA).

\section{Conclusion}

Our results clearly evidence a large vulnerability of radial growth of Douglas-fir to drought events at different scales from the region to the stand. In addition, they emphasize the importance of quantifying soil water balance, integrating bioclimatic variability (rainfall and potential evapotranspiration), 
local soil properties and leaf area index. The latter one could be managed by thinning, to cope with a future increase in the frequency and intensity of drought events: canopy leaf area index may be managed by density reduction in order to reduce the frequency and the intensity of periods of soil water shortage. Two aspects of vulnerability are important for growth recovery after recurrent drought episodes: (1) bio-indicated nutrient availability has a positive effect and (2) growth recovery is more restricted on the most productive sites. Potential trades-offs between productivity and vulnerability, such as carbon allocation to carbohydrate storage vs. growth and above vs. below ground partitioning, suggest challenging research questions that need to be addressed in future investigations.

Acknowledgments We gratefully thank F. Gérémia, Y. Lefèvre, N. Métral, P. Behr, T. Paul and B. Issenut for their technical assistance during field data collection and F. Millier for lab measurements. The field work was possible thanks to the help of the agents from CRPF in Midi-Pyrénées and Bourgogne. We also thank all forest owners who allowed tree coring.

Funding The research was funded by the National Research Agency (DRYADE project, ANR-06-VULN-004) and by the Regional Council of Bourgogne. A.S. Sergent received a $\mathrm{PhD}$ grant from the Regional Council of Région Centre, France.

\section{References}

Allen CD, Macalady AK, Chenchouni H, Bachelet D, McDowell N, Vennetier M, Kitzberger T, Rigling A, Breshears DD, Hogg EH, Gonzalez P, Fensham R, Zhang Z, Castro J, Demidova N, Lim JH, Allard G, Running SW, Semerci A, Cobb N (2010) A global overview of drought and heat-induced tree mortality reveals emerging climate change risks for forests. For Ecol Manage 259:660-684. doi:10.1016/j.foreco.2009.09.001

Anekonda TS, Lomas MC, Adams WT, Kavanagh KL, Aitken SN (2002) Genetic variation in drought hardiness of coastal Douglasfir seedlings from British Columbia. Can J For Res 32:1701-1716

Aussenac G, Granier A (1988) Effects of thinning on water stress and growth in Douglas-fir. Can J For Res 18:100-105. doi:10.1139/ x $88-015$

Aussenac G, Granier A, Naud R (1982) Influence d'une éclaircie sur la croissance et le bilan hydrique d'un jeune peuplement de Douglas (Pseudotsuga Menziesii (Mirb.) Franco). Can J For Res 12:222231

Aussenac G, Granier A, Ibrahim M (1984) Influence du dessèchement du sol sur le fonctionnement hydrique et la croissance du douglas (Pseudotsuga menziesii (Mirb.) Franco). Acta Oecologica Plantarum 5:241-253

Becker M (1989) The role of climate on present and past vitality of silver fir forests in the Vosges mountains of north eastern France. Can J For Res 19:1110-1117

Bigler C, Bräker O, Bugmann H, Dobbertin M, Rigling A (2006) Drought as an inciting mortality factor in Scots Pine Stands of the Valais, Switzerland. Ecosystems 9:330-343

Bigler C, Gavin DG, Gunning C, Veblen TT (2007) Drought induces lagged tree mortality in a subalpine forest in the Rocky Mountains. Oikos 116:1983-1994. doi:10.1111/j.2007.0030-1299.16034.x
Black TA (1979) Evapotranspiration from Douglas fir stands exposed to soil water deficits. Water Resour Res 15:164-170

Bravo-Oviedo A, Montero G (2005) Site index in relation to edaphic variables in stone pine (Pinus pinea L.) stands in south west Spain. Ann For Sci 62:61-72

Bréda N, Badeau V (2008) Forest tree responses to extreme drought and some biotic events: towards a selection according to hazard tolerance? CR Geosci 340:651-662. doi:10.1016/j.crte.2008.08.003

Bréda N, Granier A, Aussenac G (1995) Effects of thinning on soil water balance and trees water relations, transpiration and growth in an oak forest (Quercus petraea). Tree Physiol 15:295-306

Bréda N, Huc R, Granier A, Dreyer E (2006) Temperate forest trees and stands under severe drought: a review of ecophysiological responses, adaptation processes and long-term consequences. Ann For Sci 63:623-642. doi:10.1051/forest:2006042

Brix H, Mitchell A (1983) Thinning and nitrogen fertilization effects on sapwood development and relationships of foliage quantity to sapwood area and basal area in Douglas-fir. Can J For Res 13:384-389

Carnicer J, Coll M, Ninyerola M, Pons X, Sanchez G, Peñuelas J (2011) Widespread crown condition decline, food web disruption, and amplified tree mortality with increased climate change-type drought. PNAS 108:1474-1478

Carter RE, Otchere-Boateng J, Klinka K (1984) Dieback of a 30-yearold Douglas-fir plantation in the Britain River Valley, British Columbia: symptoms and diagnosis. For Ecol Manag 7:249 263. doi:10.1016/0378-1127(84)90002-1

Chen P-Y, Welsh C, Hamann A (2010) Geographic variation in growth response of Douglas-fir to interannual climate variability and projected climate change. Global Change Biol 16:3374-3385. doi:10.1111/j.1365-2486.2010.02166.x

Cook ER, Perters K (1981) The smoothing spline: a new approach to standardizing forest interior tree-ring width series for dendroclimatic studies. Tree-Ring B 41:45-53

deKort I (1993) Wood production and latewood percentage of Douglas-fir from different stands and vitality classes. Can J For Res 23:1480-1486

Ellenberg H, Weber HE, Düll R, Wirth V, Werner W, Paulissen D (1992) Zeigerwerte von Pflanzen in Mitteleuropa. Scripta Geobotanica 18:1-258

Galiano L, Martínez-Vilalta J, Lloret F (2010) Drought-induced multifactor decline of Scots Pine in the Pyrenees and potential vegetation change by the expansion of co-occurring Oak species. Ecosystems 13:978-991. doi:10.1007/s10021-010-9368-8

Galiano L, Martínez-Vilalta J, Lloret F (2011) Carbon reserves and canopy defoliation determine the recovery of Scots pine $4 \mathrm{yr}$ after a drought episode. New Phytol 190:750-759. doi:10.1111/j.14698137.2010.03628.x

Granier A (1987) Evaluation of transpiration in a Douglas-fir stand by means of sap flow measurements. Tree Physiol 3:309-320

Granier A, Bréda N, Biron P, Villette S (1999) A lumped water balance model to evaluate duration and intensity of drought constraints in forest stands. Ecol Mod 116:269-283

Griesbauer H, Green D (2010) Regional and ecological patterns in interior Douglas-fir climate-growth relationships in British Columbia, Canada. Can J For Res 40:308-321. doi:10.1139/X09-197

Guay R, Gagnon R, Morin H (1992) A new automatic and interactive tree-ring measurement system based on a line scan camera. For Chron 68:138-141

Jassal RS, Black TA, Cai T, Ethier G, Pepin S, Brümmer C, Nesic Z, Spittlehouse DL, Trofymow JA (2010) Impact of nitrogen fertilization on carbon and water balances in a chronosequence of three Douglas-fir stands in the Pacific Northwest. Agr For Met 150:208-218. doi:10.1016/j.agrformet.2009.10.005

Jolly WM, Dobbertin M, Zimmermann NE, Reichstein M (2005) Divergent vegetation growth response to the 2003 heat wave in 
the Swiss Alps. Geophys Res Lett 32:L18409. doi:10.1029/ 2005GL023252

Kohler M, Sohn J, Nägele G, Bauhus J (2010) Can drought tolerance of Norway spruce (Picea abies (L.) Karst.) be increased through thinning? Eur J Forest Res 129:1109-1118. doi:10.1007/s10342010-0397-9

Lévy G, Becker M, Lefèvre Y, Schipfer R (1987) Le dépérissement du sapin dans les Vosges: rôle primordial de déficits d'alimentation en eau. Ann For Sci 44:403-416. doi:10.1051/forest:19870402

Littell JS, Peterson DL, Tjoelker M (2008) Douglas-fir growth in mountain ecosystems: water limits tree growth from stand to region. Ecol Monographs 78:349-368. doi:10.1890/07-0712.1

Lorenz M, Fischer R, Becher G, Granke O, Riedel T, Roskams P, Nagel H-D, Kraft P (2007) Forest Condition in Europe. 2007 Technical Report. $91 \mathrm{p}$

Manion PD (1981) Tree disease concepts. Prentice-Hall, Englewood Cliffs, p 399

Marques R, Ranger J, Villette S, Granier A (1997) Nutrient dynamics in a chronosequence of Douglas-fir (Pseudotsuga menziesii (Mirb). Franco) stands on the Beaujolais Mounts (France). 2. Quantitative approach. For Ecol Manag 92:167-197. doi:10.1016/S0378-1127 (96)03913-8

Marshall JD, Waring RH (1986) Comparison of methods of estimating leaf-area index in old-growth Douglas-Fir. Ecol 67:975. doi: $10.2307 / 1939820$

Martinez-Meier A, Sanchez L, Pastorino M, Gallo L, Rozenberg P (2008) What is hot in tree rings? The wood density of surviving Douglas-firs to the 2003 drought and heat wave. For Ecol Manag 256:837-843. doi:10.1016/j.foreco.2008.05.041

Misson L, Ponette Q, Andre F (2001) Regional scale effects of base cation fertilization on Norway spruce and European beech stands situated on acid brown soils: soil and foliar chemistry. Ann For Sci 58:699-712

Mitchell AK, Barclay HJ, Brix H, Pollard DFW, Benton R, deJong R (1996) Biomass and nutrient element dynamics in Douglas-fir: effects of thinning and nitrogen fertilization over 18 years. Can $\mathrm{J}$ For Res 26:376-388. doi:10.1139/x26-042

Mueller R, Scudder C, Porter M, Talbot Trotter R III, Gehring C, Whitham T (2005) Differential tree mortality in response to severe drought: evidence for long-term vegetation shifts. J Ecol 93:1085-1093. doi:10.1111/j.1365-2745.2005.01042.x

Nigh G (2006) Impact of climate, moisture regime, and nutrient regime on the productivity of Douglas-Fir in coastal British Columbia, Canada. Clim Chang 76:321-337. doi:10.1007/s10584-005-9041-y

Parmesan C, Yohe G (2003) A globally coherent fingerprint of climate change impacts across natural systems. Nature 421:37-42. doi:10.1038/nature01286

Pichler P, Oberhuber W (2007) Radial growth response of coniferous forest trees in an inner Alpine environment to heat-wave in 2003. For Ecol Manag 242:688-699. doi:10.1016/j.foreco.2007.02.007

R Development Core Team (2008) R: a language and environment for statistical computing. R Foundation for Statistical Computing, Vienna, ISBN 3-900051-07-0, URL http://www.R-project.org
Ranger J, Turpault M-P (1999) Input-output nutrient budgets as a diagnostic tool for sustainable forest management. For Ecol Manag 122:139-154. doi:10.1016/S0378-1127(99)00038-9

Rebetez M, Mayer H, Dupont O, Schindler D, Gartner K, Kropp J, Menzel A (2006) Heat and drought 2003 in Europe: a climate synthesis. Ann For Sci 63:569-577. doi:10.1051/forest:2006043

Reich RW, van der Kamp BJ (1993) Frost, canker, and dieback of Douglas-fir in the central interior of British Columbia. Can J For Res 23:373-379. doi:10.1139/x93-054

Sarris D, Christodoulakis D, Körner Ch (2007) Recent decline in precipitation and tree growth in the eastern Mediterranean. Glob Change Biol 13:1187-1200

Schär C, Vidale PL, Lüthi D, Frei C, Häberli C, Mark A, Liniger MA, Appenzeller C (2004) The role of increasing temperature variability in European summer heatwaves. Nature 427:332-336. doi: $10.1038 /$ nature 02300

Solberg S (2004) Summer drought: a driver for crown condition and mortality of Norway spruce in Norway. For Pathol 34:93-104. doi:10.1111/j.1439-0329.2004.00351.x

St Clair JB (1993) Family differences in equations for predicting biomass and leaf area in Douglas-fir (Pseudotsuga menziesii var. menziesii). For Sci 39:743-755

Suarez ML, Ghermandi L, Kitzberger T (2004) Factors predisposing episodic drought-induced tree mortality in Nothofagus site, climatic sensitivity and growth trends. J Ecol 92:954-966. doi:10.1111/j.1365-2745.2004.00941.x

Turner BL, Kasperson RE, Matson PA, McCarthy JJ, Corell RW, Christensen L, Eckley N, Kasperson JX, Luers A, Martello ML, Polsky C, Pulsipher A, Schiller A (2003) A framework for vulnerability analysis in sustainability science. Proc Natl Acad Sci U S A 100:8074-8079. doi:10.1073/pnas. 1231335100

Van Praag HJ, Weissen F (1986) Foliar mineral composition, fertilization and dieback of Norway spruce in the Belgian Ardennes. Tree Physiol 1:169-176. doi:10.1093/treephys/1.2.169

Vidal JP, Martin E, Franchist'eguy L, Baillon M, Soubeyroux JM (2010a) A 50-year high-resolution atmospheric reanalysis over France with the Safran system. Int J Climatol 30:1627-1644

Vidal JP, Martin E, Franchist'eguy L, Habets F, Soubeuroux JM, Blanchard M, Baillon M (2010b) Multilevel and multiscale drought reanalysis over France with the Safran-Isba-Modcou hydrometeorological suite. Hydrol Earth Syst Sci 14:459-478

Vilá-Cabrera A, Martínez-Vilalta J, Vayreda J, Retana J (2011) Structural and climatic determinants of demographic rates of Scots pine forests across the Iberian Peninsula. Ecol Appl 21:1662-1172

Wang GG (2000) Use of understory vegetation in classifying soil moisture and nutrient regimes. For Ecol Manag 129:93-100

Watson E, Luckman BH (2002) The dendroclimatic signal in Douglasfir and ponderosa pine tree-ring chronologies from the southern Canadian Cordillera. Can J For Res 32:1858-1874. doi:10.1139/ x02-096

Wösten JHM, van Genuchten MT (1988) Using texture and others soil properties to predict the unsaturated soil hydraulic functions. Soil Sci Soc Am J 52:1762-1770 